\title{
Photodegradation of a polypropylene filled with lanthanide complexes
}

\author{
Valérie Massardier1*and Molka Louizi ${ }^{1}$
}

\begin{abstract}
1 'UMR 5223 Ingénierie des Matériaux Polymères, Centre National de la Recherche Scientifique - CNRS, Institut National des Sciences Appliquées de Lyon - INSA Lyon, Villeurbanne, France

*valerie.massardier@insa-lyon.fr
\end{abstract}

\begin{abstract}
This research aims at studying the photodegradation of a polypropylene formulation filled with lanthanide complexes. These complexes can be used as tracers for the identification of polymer materials in order to facilitate an high speed automatic sorting of plastic wastes for an economically efficient recycling. By paying attention to the evolution of carbonyl absorption bands in FTIR spectra, it is observed that the addition of lanthanide complexes into our formulation improves UV stability of polypropylene by reducing the extent of photo-degradation. Furthermore, TG analyses show that the traced blends can maintain better thermal properties, after irradiation. A significant increase of the crystallinity degree and a decrease of the melting temperature are more pronounced for the unfilled UV-irradiated PP. This might result from chemi-crystallization that can occur when chain entanglements are broken as a result of chain scissions. From SEM analyses, it is observed that the severity of surface cracks induced by photo degradation is reduced for filled PP. The mechanical tests are in agreement with this result and show a fundamental change in the behavior of the as-exposed blends from a ductile to a brittle material.
\end{abstract}

Keywords: polypropylene, lanthanide complexes, UV irradiation, photodegradation.

\section{Introduction}

The commercial importance of polymers has lead to very large applications in the form of composites/nanocomposites, polymer blends ${ }^{[1-4]}$, such as automotive, aerospace, packaging, etc. Whatever the application and especially outdoor ones, there is often a natural concern regarding the durability of polymer materials. Commonly known, the durability of any material depends on several factors such as the environment (especially sunlight intensity, temperature, moisture, etc.), the exposure time, the type of polymer (presence of thermal and UV stabilizers, etc.), water absorption, etc ${ }^{[5]}$. Among these factors, ultra violet (UV) irradiation is a frequently encountered factor that can induce photo-degradation of polymers.

Polypropylene (PP) is one of the most used polyolefins, with a significant part of its applications corresponding to outdoor environments. For this reason, a lot of studies are focused on the understanding of the mechanisms of UV-induced degradation of $\mathrm{PP}^{[6-9]}$ and polyolefins ${ }^{[10,11]}$. Photolytic degradation and photo-oxidation are the most important phenomenon observed when irradiating PP within the active range $[310-350 \mathrm{~nm}]^{[5,12]}$. These reactions preferentially occur in the amorphous fraction because of its high permeability to oxygen ${ }^{[13]}$. Photolysis primarily involves the adsorption of wavelengths above $290 \mathrm{~nm}$ in the UV regions of the solar spectrum by chromophores (or impurities) which in turn release sufficient energy to cause bond scissions resulting in the formation of radicals that can either combine to form more chromophores or initiate photo-oxidation ${ }^{[14]}$. It is worth noting that these mechanisms occur in the UV degradation of PP and lead to main changes in their chemical, physical and mechanical properties. It is generally known that the photodegradation

induces a change in the melting and cristallinity behaviors of PP. The melting temperature decrease is ascribed to i) oxidative reactions on crystal surface that increase the surface free energy of the crystals and ii) new crystals formed from polymer released by degradation that may have a lower melting temperature than the pre-existing crystals because of the defects content (crosslinks, carbonyl groups, etc) ${ }^{[15]}$. As regards the cristallinity, the freed segments, formed by molecular chain scissions, form a new crystalline structure in the amorphous zone, especially at high exposure temperature (about $65^{\circ} \mathrm{C}$ ) and thus provoke the growth of pre-existing crystals of $\mathrm{PP}^{[16]}$. This increase in crystallinity is a form of secondary crystallization often known as chemi-crystallization ${ }^{[17]}$. It should be noted that the increase in crystallinity is limited by the presence of chemical irregularities such as carbonyls and hydroperoxides that form progressively under photooxidation. Thus, there are two opposite effects, one that promotes greater crystallinity and the other inhibiting crystallization. The shorter chains produced by scission events will crystallize more rapidly whereas crosslinks and molecular defects (carbonyls, etc.) will not be able to crystallize and will be rejected from the newly formed crystals. In addition, the phenomena occurring during the PP photodegradation (chain scissions and in turn shrinkage) lead to the development of tensile residual stresses near the surface ${ }^{[6]}$. A severe deterioration of engineering properties may therefore occur. The most important practical consequence of chemi-crystallization is the formation of cracks caused by contraction of the surface layers ${ }^{[18]}$. The presence of surface cracks is indeed one of the main reasons for the embrittlement of ductile semi-crystalline polymers such as PP, causing serious deterioration in the 
mechanical properties of the polymer after short-term exposures ${ }^{[16,19]}$. In order to decrease the UV degradation and extend the lifetime of PP polymer, there is a growing interest in adding UV screeners to bulk polymers during processing. The photolysis of PP is induced by adsorption of UV light causing the formation of free radicals. Those radicals can react with oxygen to yield hydroperoxides and then carbonyl groups ${ }^{[12,14]}$.

There are also several studies focusing on the thermal stability and photo-degradation mechanisms for the obtained nanocomposites. Carbon black $(\mathrm{CB})$ has been considered as the most effective organic UV screener as it absorbs all incident lights with its phenolic and quinoid groups functioning as anti-oxidants ${ }^{[20]}$. As regards the inorganic compounds, the zinc oxide proved to have a relatively high adsorption band starting at $385 \mathrm{~nm}$ and extending to the far-UV ${ }^{[21]}$. It is shown that zinc oxide, as a UV-screening additive, does not degrade when absorbing light and in many cases may improve mechanical, optical and electronic properties ${ }^{[12]}$. In terms of UV damage, it is also found that layered silica filled polymer composites exhibit remarkable improvement of mechanical, thermal properties when compared with pure polymer due to interactions of fillers with the polymer matrix at the nano-level scale ${ }^{[22]}$. Zhao and $\mathrm{Li}^{[23]}$ show that the extent of photodegradation is significantly reduced with the addition of $\mathrm{ZnO}$ nanoparticles in PP matrix. This is ascribed to the superior UV light screening effects offered by the $\mathrm{ZnO}$ nanoparticles. Despite several researches focused on the study of the photo-degradation of polymers filled with nanosilica, zinc oxide, carbon black, MMT, etc only few studies deal with polymers containing rare earth oxides $^{[24-26]}$. Recently, Bezati et al. ${ }^{[2]}$ have shown that the addition of $1 \mathrm{wt} \%$ of cerium oxide nanoparticles improves the photo-degradation resistance of PP matrix to UV exposure due to the light screening effects offered by these particles.

As outlined above, the oxidation of PP chains can be reduced by adding specific fillers (nanosilica, zinc oxide, carbon black, MMT, rare earth oxide, etc) acting as UV filters and hence protects the polymer from UV intensity. Therefore, in the present article, we are interested in the photodegradation of polypropylene filled with lanthanide complexes that can be used as tracers for the identification of polymer materials (especially black ones), in order to facilitate high speed automatic sorting of plastic wastes for an economically efficient recycling. The feasibility of the detection of these lanthanide complexes dispersed in white and black PP matrices was successfully achieved in previous studies $^{[28]}$ through the use of UV-ray fluorescence spectrometry. Furthermore, the elaboration of traced blends via high shear process ${ }^{[29,30]}$ has proved to be a major key for preparation of well dispersed tracer particles within polypropylene matrix especially when processing at a screw speed, $\mathrm{N}$, equal to $800 \mathrm{rpm}$.

The present study was conducted to gain a good knowledge of the subsequent changes occurring in the properties of traced black polypropylene with lanthanide complexes under UV irradiation. In our case, for accelerating ageing phenomenon, the surface of the traced blends was UV-irradiated at $60^{\circ} \mathrm{C}$ for 3 months (2160 hours). The effectiveness of lanthanide complexes particles on combating UV irradiation damage for PP is evaluated through various analyses to characterize evolutions in chemical structures (FTIR), in morphologies (MEB), in thermal properties (TGA, DSC), as well as in mechanical properties (tensile and impact tests).

\section{Materials and Methods}

\subsection{Materials}

The polymer investigated in this study is a commercial grade, BMU 133, used in the automotive as well as in the electrical \& electronic fields. BMU 133 is a black polypropylene copolymer provided by Exxon Mobil Chemicals. It contains $15 \mathrm{wt} \%$ of elastomer and $10 \mathrm{wt} \%$ of carbon black (CB) shows a Melt Flow Index MFI $=15 \mathrm{~g} / 10$ min under $2.16 \mathrm{~kg}$ at $230^{\circ} \mathrm{C}$ and a specific gravity $=0.970 \mathrm{~g} / \mathrm{cm}^{3}$.

Two fluorescent tracers (T2 and T3) were tested and belong to the inorganic family of the lanthanide complexes. $\mathrm{T} 2$ is a doped aluminum and barium oxide, $\mathrm{T} 3$ is a doped vanadium trioxide. These tracers do not chemically react with the materials and were provided by the start up Tracing Technologies. They are thermally stable at high temperatures, compatible with the REACH regulations. Their essential feature is that when they are excited with a UV source between 300 and $400 \mathrm{~nm}$, they fluoresce in the visible light spectrum.

\subsection{Elaboration of traced blends}

All blends filled with $0.1 \mathrm{wt} \%$ of fluorescent tracers (T2 or T3) were prepared with a co-rotating twin screw-extruder (TSE) Leistritz ZSE $18 \mathrm{HP}$. The screw profile, with a screw diameter of $18 \mathrm{~mm}$ and a $\mathrm{L} / \mathrm{D}$ ratio of 60 , used for all the experiments is illustrated in Figure 1.

The originality of this extruder lies on reaching high shear rates on extruded blends by adjusting the screw rotation speed. In addition, in the first part of this study, this technique has proved to be a key for the preparation of well-dispersed tracer

\section{Inlet}

Outlet

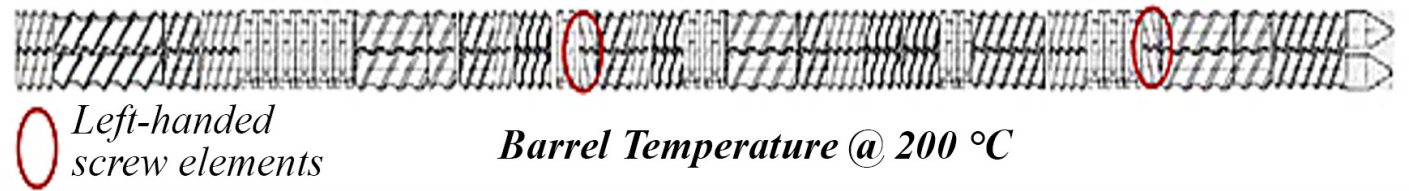

Figure 1. Screw configuration of the co-rotating high shear extruder (Leistritz ZSE 18 HP). 
particles within polypropylene matrix. The screw speed, the mean residence time and the feed rate $(\mathrm{Q})$ were $800 \mathrm{rpm}$, $55 \mathrm{~s}$, and $3 \mathrm{~kg} / \mathrm{h}$ respectively. The chosen rotation speed, $800 \mathrm{rpm}$, corresponds to a shear rate of $500 \mathrm{~s}^{-1}$ calculated thanks to Ludovic software ${ }^{[31]}$. The extrusion temperature was fixed at $200^{\circ} \mathrm{C}$ but the experimental melt temperature at the die exit was about $235^{\circ} \mathrm{C}$, measured by introducing a thermocouple into the bulk extrudate. All traced blends were prepared under identical mixing and moulding conditions.

At the die exit of the extruder, the extrudates are pelletized and then moulded at $200^{\circ} \mathrm{C}$ through a Battenfeld 350 PLUS injection moulding machine. Standard tensile and rectangular bars are produced for mechanical analyses.

\subsection{UV irradiation}

As regards the photodegradation of the traced blends, a UV irradiation treatment was accomplished for the injected samples using a QUV accelerated weathering machine (Q-panel lab products, UVA $340 \mathrm{~nm}$ ), with a light intensity of $0.68 \mathrm{~W} / \mathrm{m}^{2}$. QUV accelerated weathering was used to simulate long-term exposure. The source of UV irradiation was fluorescent tubes UVA-340, with an output responsibly close to the solar radiation in the UV range (Labomat). The surface of samples was UV irradiated at a controlled temperature of $60^{\circ} \mathrm{C}$ for an exposure time of 3 months ( 2160 hours). The traced blends containing $0.1 \mathrm{wt} \%$ of tracers (T) and UV irradiated will be designed as UV- (for example: UV-BMU 133-T3-0.1) and the non-irradiated will be referred as polymer type-T-0.1 (for instance: BMU 133-T3-0.1).

\subsection{Infrared spectrometry}

UV irradiated traced blends were characterized by Fourier Transform Infrared spectrometry (FTIR). Samples of about $0.4 \mathrm{~mm}$ thick were cut from the surface of the plates and observed. The FTIR-ATR measurements were obtained in absorption mode by using 16 scans at $2 \mathrm{~cm}^{-1}$. PP molecular degradation is characterized by calculation of a carbonyl index $(\mathrm{CI})$, which was calculated by the following equation:

$$
C I=\frac{A_{c}}{A_{R}}
$$

Where $A_{c}$ represents the area of the carbonyl absorption band being in the range $\left[1700-1800 \mathrm{~cm}^{-1}\right]$ and $A_{R}$ is the area of the reference band in the range $\left[2700-2750 \mathrm{~cm}^{-1}\right]^{[23]}$. The reference peak corresponds to the $\mathrm{CH}_{3}$ stretching and $\mathrm{CH}$ bending ${ }^{[16]}$.

\subsection{Thermal properties}

The thermal properties of blends before and after UV irradiation were carried out by Differential Scanning Calorimetry by using DSC Q10 of TA instruments. To perform these tests, samples were cut into pellets and placed in aluminum pans. A scan was performed from 10 to $200^{\circ} \mathrm{C}$, further maintained for $2 \mathrm{~min}$ at $200^{\circ} \mathrm{C}$ to erase the thermal history of the blends and then cooled down from $200^{\circ} \mathrm{C}$ to $10^{\circ} \mathrm{C}$. The heating and cooling rates were fixed at $10^{\circ} \mathrm{C} / \mathrm{min}$. The crystallization degree, $\mathrm{X}_{\mathrm{C}}$, is calculated by considering a melting enthalpy of $209 \mathrm{~J} / \mathrm{g}$ for a $100 \%$ crystalline polypropylene.
To characterize the thermal stability of samples before and after UV irradiation, thermogravimetric analyses with TA Q500 apparatus were carried out. The measurements were conducted under an argon flow rate at heating rates of $20^{\circ} \mathrm{C} / \mathrm{min}$. The scanning temperature was in the range $\left[25-600^{\circ} \mathrm{C}\right]$. The temperature of maximum decomposition rate was determined for all the blends.

It is worth noting that after UV treatment, prior to DSC and TGA analyses, thin slices of samples, about $0.4 \mathrm{~mm}$ thick, were cut from surfaces of the molded plates for the measurements.

\subsection{Morphology observation}

The dispersion of tracers in the selected polymers was investigated by Scanning Electron Microscopy (SEM) with a Hitashi S800 model at an accelerating voltage of $30 \mathrm{kV}$. Prior to observations, samples were cryo-fractured in liquid nitrogen to avoid any plastic deformation. SEM was also used to observe the surface cracking of samples after UV irradiation.

\subsection{Mechanical tests}

Tensile tests were carried out by means of an Instron machine MTS 2/M tester, at a crosshead speed of $30 \mathrm{~mm} / \mathrm{min}$ at room temperature. Impact tests were performed by means of a Zwick D7900 Type 5102-100/00 instrument in compliance with standard ISO 179 on notched specimens conditioned at $-22^{\circ} \mathrm{C}$ for $48 \mathrm{~h}$. These tests were conducted in order to obtain the Young's Modulus, elongation at break, tensile and impact strengths before and after irradiation treatment. All the reported values are the averages of ten experimental results to check the reproducibility.

\section{Results and Discussions}

\subsection{Evolution of chemical structures}

As shown previously, the photodegradation process of materials corresponds to radical reactions in chains that can be initiated by the presence of impurities and high energy photon collision ${ }^{[23]}$. By using FTIR spectroscopy, it is easy to identify the degradation products generated by macroradical oxidation. In previous researches ${ }^{[32,33]}$, it was shown that the photo-degradation of PP causes mainly the formation of hydroperoxides and carbonyls easily observed in the wavenumber ranges $\left[3200-3600 \mathrm{~cm}^{-1}\right]$ and $\left[1700-1800 \mathrm{~cm}^{-1}\right]$ respectively. In this study, evolutions of the FTIR spectra of UV-BMU133, UV-BMU133-T2 or T3 were examined in the wavenumber range $\left[1700-1800 \mathrm{~cm}^{-1}\right]$ (Figure 2) and the carbonyl index of these samples after UV-treatment was also calculated by using Equation 1 and displayed in Figure 3. The spectrum of unfilled BMU133 before irradiation was also carried out for comparison.

As expected, the UV-BMU133 blend presents an intense peak in the carbonyl region [1700-1800 $\mathrm{cm}^{-1}$ ] after UV irradiation. For the irradiated samples containing T3 or T2 tracer, the carbonyl peak intensity is decreased as well as the carbonyl index compared to UV-BMU133 blends (Figures 2 and 3). This can be ascribed to the effect of tracer particles which 

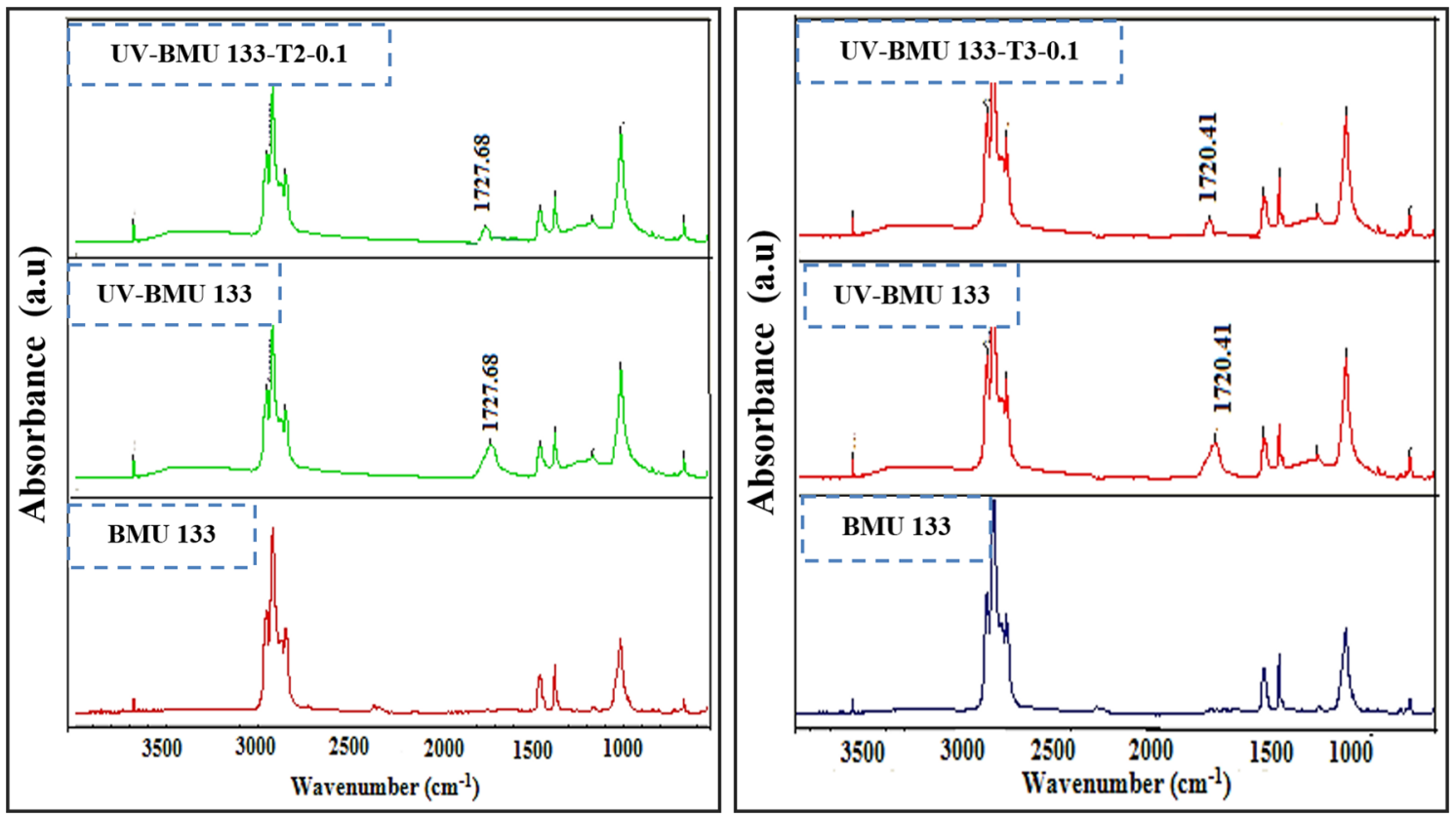

Figure 2. FTIR spectra of UV irradiated BMU133 and its traced blends with T2 or T3.
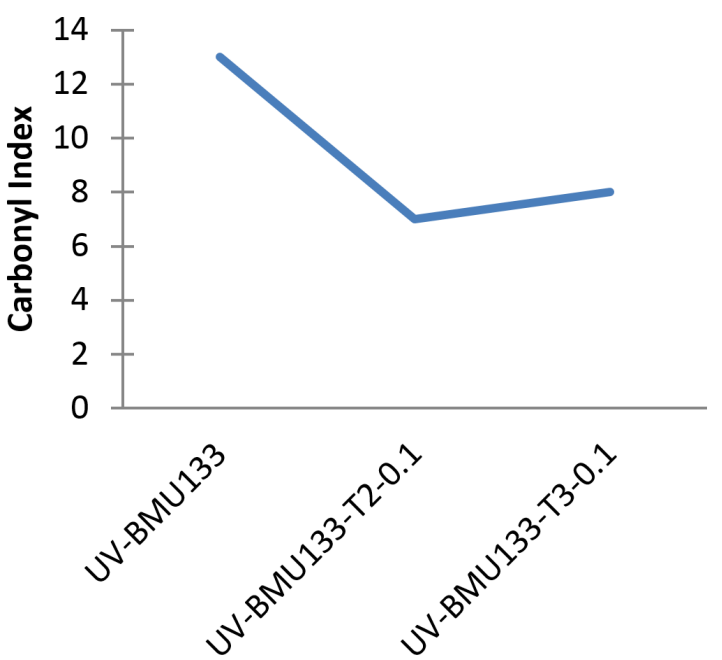

Figure 3. Carbonyl index of UV-BMU133, UV-BMU133-T2-0.1 or T3-0.1.

contributes to the stabilization of PP chains and delay the photodegradation process by acting as screens. To play this role, tracer particles must absorb a part of UV irradiation and thus contribute to the decrease of UV intensity that can promote the oxidation of the PP chains. Furthermore, the mechanism of photo degradation of UV-BMU133 without or with $\mathrm{T} 2$ or $\mathrm{T} 3$ tracer after irradiation is identical and no additional peak appears when adding tracers. These findings are in good agreement with those observed by Bezati et al. ${ }^{[27]}$ for PP samples containing rare earth particles exposed to UV irradiation. Similar stabilization effect is observed for metal oxides by several authors ${ }^{[25,26]}$.

\subsection{Effect of UV irradiation on the thermal properties of traced blends}

To have an insight on the effect of UV irradiation treatment on thermal properties of unfilled BMU133 and its traced blends, DSC and TGA analyses were carried out. The results in terms of melting/crystallization temperatures and enthalpies as well as the temperature at maximum weight loss $\left(\mathrm{T}_{\max }\right)$ of these samples are summarized in Table 1. On a one hand, it is well observed that the UV irradiation treatment has a considerable effect on the crystallization and melting behaviors of the treated samples (Table 1). The melting and crystallization temperatures of UV irradiated BMU133 shift to lower temperatures from 168.2 to $151.5^{\circ} \mathrm{C}$ for $\mathrm{Tm}$ and from 124.0 to $112.8^{\circ} \mathrm{C}$ for Tc. Furthermore, a reduction in $\mathrm{T}_{\mathrm{m}}$ is shown for all the UV irradiated traced blends due to the UV irradiation. Such an effect is expected because the photo-degradation causes chain scissions resulting in the formation of more freed segments ${ }^{[16,23]}$. This contributes to a drop off of molecular weight of materials and consequently leads to a decrease of the melting temperature ${ }^{[27]}$. The decrease in melting temperature can also be due to oxidative reactions on the crystal surface that increase the surface free energy of the crystals $^{[15,34]}$. Similar trends were observed by Bezati et al. ${ }^{[27]}$ and Rabello and White ${ }^{[16]}$ in previous studies. From Table 1, it can also be noted that the cristallinity $\left(X_{c}\right)$ of BMU133 is increased upon UV irradiation. The change in crystallization behaviour can be explained by the chemi-crystallization occurring when chain entanglements are broken as a result of chain scissions. Then, the freed segments produced by molecular chain scissions can induce the formation of new crystalline structures in the amorphous zone, especially at high exposure temperature (about $65^{\circ} \mathrm{C}$ ) and thus provoke the growth of pre-existing crystals of $\mathrm{PP}^{[16]}$. Furthermore, it 
is worth noting that the presence of chemical irregularities such as carbonyls and hydroperoxides that form progressively under photo-oxidation can also contribute to a disruption in crystallinity as shown by Zhao and $\mathrm{Li}^{[23]}$.

Regarding the crystallisation degrees $\left(\mathrm{X}_{\mathrm{c}}\right)$ of traced blends, they are not significantly affected in presence of lanthanide complexes. This can be due to the stabilization effect of tracer particles that blocks the chemi-crystallization of $\mathrm{PP}^{[16]}$.

On the other hand, it is shown that UV-irradiation impacts the thermal stability of BMU133 as well as its traced blends with T2 and T3 tracers. As reported in Table 1, the thermal decomposition of UV-BMU133 occurs at lower temperatures after irradiation compared to those being non-irradiated. This is expected because when polymer formulations are irradiated with ultraviolet radiations, they can degrade due to absorption of light energy by chemical groups present either in the same polymer or in additives and impurities. This absorption causes radical chain reaction mechanism initiated by carbon radicals due to the lack of oxygen. These primary radicals initiate and propagate the subsequent radical chain reaction and hence contribute to the degradation of materials ${ }^{[35]}$. However, Tmax of the UV irradiated BMU133/T3, BMU133/T2 are slightly increased compared to UV-BMU133. This can be ascribed to the protective effect offered by tracer particles due to their UV-screening properties inducing a good thermal stability of the traced polymers towards ultraviolet radiations ${ }^{[27]}$. For visualization purposes, the TGA curves of UV-BMU133 and UV-BMU133-T3-0.1 after irradiation treatment are depicted in Figure 4.

\subsection{Morphological properties}

It is commonly known that the degree of photo-oxidation decreases when moving deeper below the material surface owing to the limited penetration ability of UV light and oxygen diffusion. Therefore, the damage caused by UV irradiation is the formation of surface cracks inducing thereafter the embrittlement of the material ${ }^{[19,36]}$. Figure 5 compares the surface topography of the UV-BMU133 and UV-BMU133-T3-0.1 traced blend respectively. In both cases, cracks caused by UV irradiation can be clearly observed. However, the cracks on the surface of UV-PP are very coarse and propagate toward the core of the specimen while that for UV-BMU133-T3-0.1 are much finer. This suggests that damages caused by UV irradiation to the virgin BMU133 are more intense than those to the traced blend with T3 (UV-BMU133-T3-0.1). It can also be easily observed that the surface cracks are significantly reduced after addition of the tracer particles T3. The same type of surface cracks was observed for BMU133 filled with T2 tracer. As for T3 tracer, addition of the $\mathrm{T} 2$ or $\mathrm{T} 3$ microparticles can reduce the damage of UV light and oxygen diffusion on PP polymer and strengthens the resistance of PP to photodegradation.

Table 1. Thermal and crystallization data obtained from DSC and TGA analyses before and after UV irradiation.

\begin{tabular}{|c|c|c|c|c|c|c|c|}
\hline & Samples & $\begin{array}{c}\mathbf{T}_{\mathrm{m}} \\
\left({ }^{\circ} \mathrm{C}\right)\end{array}$ & $\begin{array}{c}\Delta \mathbf{H}_{\mathrm{f}} \\
\left(\mathbf{J} / \mathrm{g}_{\mathrm{PP}}\right)\end{array}$ & $\begin{array}{c}\mathbf{T}_{\mathbf{c}} \\
\left({ }^{\circ} \mathbf{C}\right)\end{array}$ & $\begin{array}{c}\Delta \mathbf{H}_{\mathrm{c}} \\
\left(\mathbf{J} / \mathrm{g}_{\mathrm{PP}}\right)\end{array}$ & $\begin{array}{c}X_{c} \\
(\%)\end{array}$ & $\begin{array}{l}\mathbf{T}_{\text {max }} \\
\left({ }^{\circ} \mathrm{C}\right)\end{array}$ \\
\hline \multirow{6}{*}{ 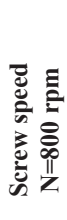 } & BMU133-reference (B) & 168.2 & 57.2 & 124.0 & 57.1 & 24.5 & 485.2 \\
\hline & UV-BMU133 & 159.6 & 65.4 & 112.8 & 67.3 & 36.3 & 460.3 \\
\hline & BMU133-T3-0.1 & 167.1 & 55.2 & 124.0 & 62.4 & 26.5 & 471.1 \\
\hline & UV-BMU133-T3-0.1 & 154.1 & 63.1 & 113.4 & 65.4 & 32.1 & 468.8 \\
\hline & BMU133-T2- 0.1 & 167.2 & 57.1 & 124.0 & 63.2 & 27.3 & 488.5 \\
\hline & UV-BMU133-T2-0.1 & 151.5 & 64.2 & 114.5 & 66.1 & 30.7 & 466.3 \\
\hline
\end{tabular}

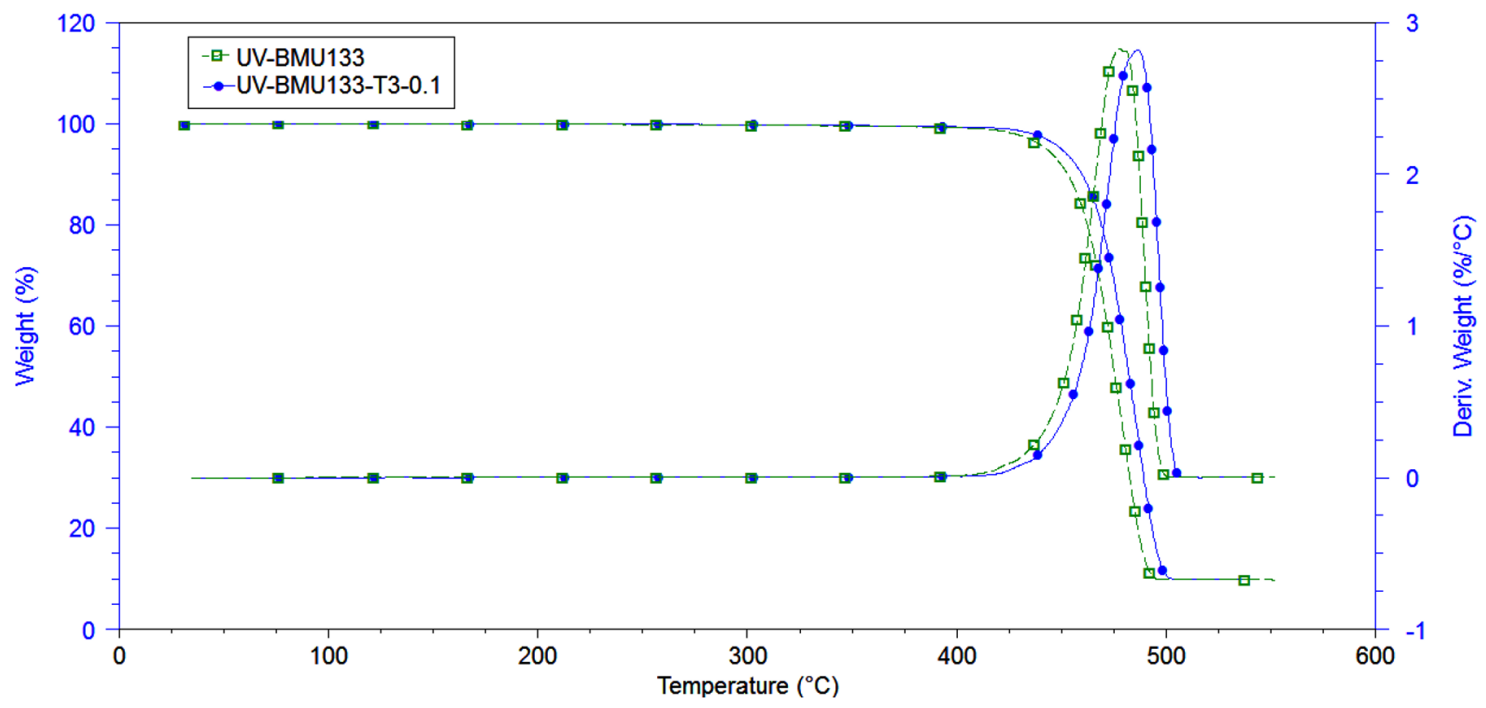

Figure 4. TGA curves of the UV-BMU 133 and UV-BMU133-T3-0.1 after irradiation. 


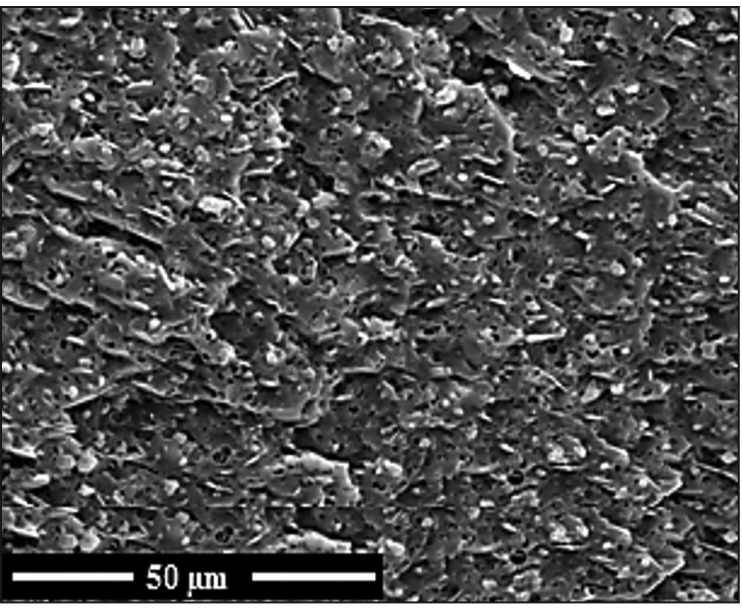

(a)

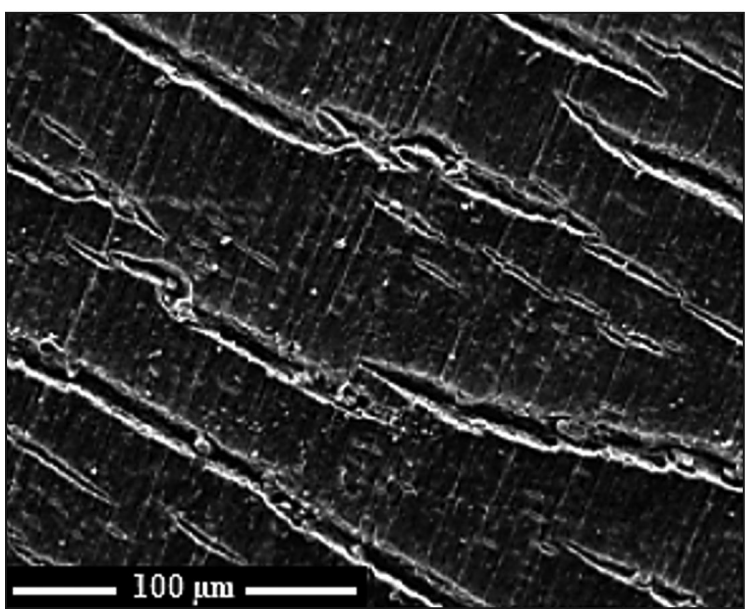

(c)

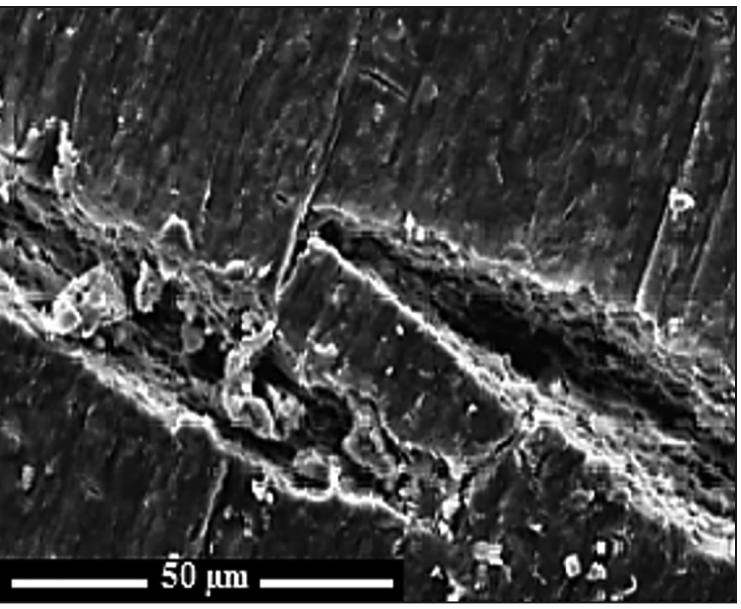

(b)

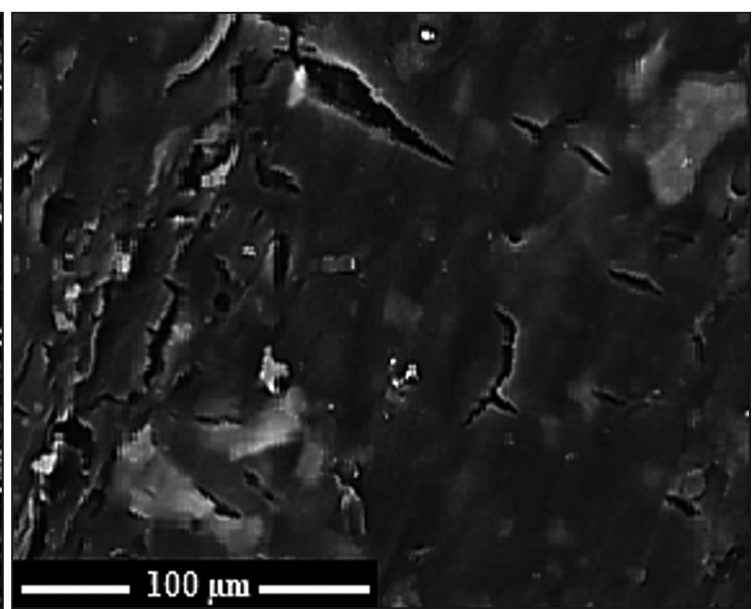

(d)

Figure 5. SEM micrographs of (a) BMU133, (b, c) UV-BMU133, (d) UV-BMU133-T3-0.1.

\subsection{Effect of UV-irradiation on the mechanical properties of traced blends}

Before UV irradiation treatment, BMU133 and its traced blends processed at $800 \mathrm{rpm}$ show a ductile behaviour (Table 2). However, after UV treatment, an intense decrease of both modulus and elongation at break is observed (Figure 6). This means that the photodegradation weakens the material and induces a fundamental change in the behavior of the as-exposed samples blends from ductile to brittle material. This behaviour is in agreement with the chemi-crystallization caused by the degradation process of PP, which contributes to the formation of surface cracks due to the contraction of the surface layer ${ }^{[16,18]}$. Furthermore, in addition to chemi-crystallization, crosslinks and chain scissions can lead to the embrittlement of materials and it is also noted that the accumulation of defects (carbonyl, hydroperoxyde groups, etc.) on the chains in the amorphous phase induces the formation of tensile residual stresses ${ }^{[37,38]}$.

In addition, the presence of surface cracks, as seen previously on SEM micrographs (Figure 5), can be considered as one of the reasons for the embrittlement of the material, causing
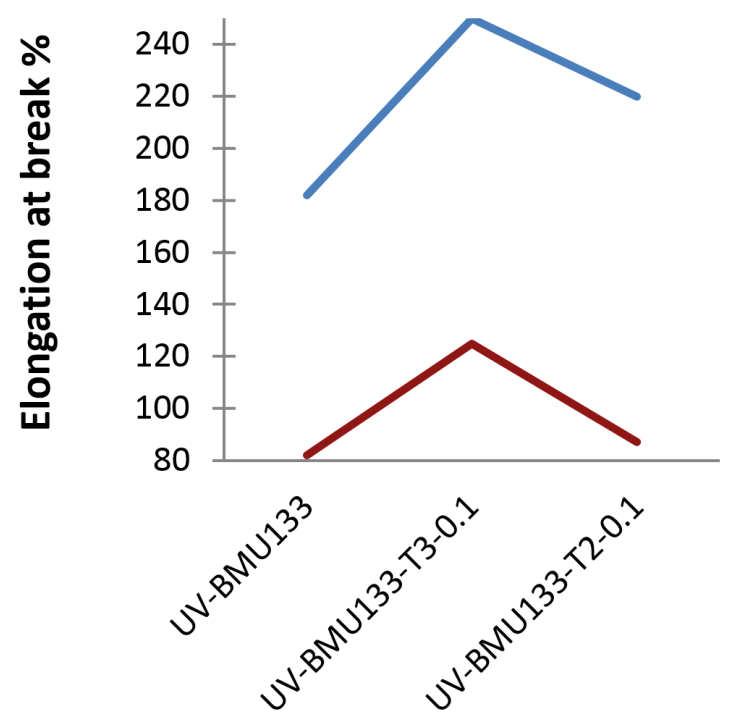

Figure 6. Elongation at break of samples before — and after UV irradiation. 
Table 2. Mechanical properties (E: Young Modulus, $\boldsymbol{\sigma}_{\mathbf{b}}$ : strain at break, $\boldsymbol{\varepsilon}_{\mathbf{b}}$ : elongation at break) of samples before and after UV irradiation.

\begin{tabular}{|c|c|c|c|c|c|c|}
\hline \multicolumn{3}{|r|}{ Samples } & $\begin{array}{c}\mathrm{E} \\
(\mathrm{MPa})\end{array}$ & $\begin{array}{c}\sigma_{\mathrm{b}} \\
(\mathrm{MPa})\end{array}$ & $\begin{array}{c}\varepsilon_{\mathrm{b}} \\
(\%)\end{array}$ & $\begin{array}{c}\text { Impact Strength } \\
\left(\mathrm{kJ} / \mathrm{m}^{2}\right)\end{array}$ \\
\hline \multicolumn{3}{|c|}{ BMU133-reference (B) } & $420 \pm 10$ & $13 \pm 01$ & $187 \pm 10$ & $7 \pm 01$ \\
\hline \multicolumn{3}{|c|}{ UV-BMU133 } & $204 \pm 04$ & $8 \pm 01$ & $87 \pm 07$ & $3 \pm 01$ \\
\hline \multirow{4}{*}{ 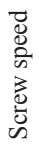 } & \multirow{4}{*}{ 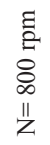 } & BMU133-T3- 0.1 & $410 \pm 08$ & $13 \pm 01$ & $251 \pm 10$ & $12 \pm 01$ \\
\hline & & UV-BMU133-T3- 0.1 & $198 \pm 08$ & $9 \pm 01$ & $121 \pm 10$ & $5 \pm 01$ \\
\hline & & BMU133-T2- 0.1 & $430 \pm 08$ & $12 \pm 01$ & $224 \pm 07$ & $11 \pm 02$ \\
\hline & & UV-BMU133-T2- 0.1 & $187 \pm 02$ & $8 \pm 01$ & $93 \pm 10$ & $6 \pm 01$ \\
\hline
\end{tabular}

a serious deterioration in the mechanical properties of the products even after short term exposures ${ }^{[19]}$. Consequently, the presence of these cracks facilitates the failure.

\section{Conclusions}

Results from this research show that the addition of tracer particles into a commercial PP formulation can impart an improvement in photodegradation resistance of PP to UV-irradiation. The tracers were stable after ageing tests. From FTIR analysis, it is observed that the intensity of carbonyl absorption for traced blends in the wavenumber region $\left[1700-1800 \mathrm{~cm}^{-1}\right]$ is reduced in presence of tracer particles compared to the unfilled material. This is ascribed to the protective effect offered by tracer particles due to their UV-screening properties which can retard the oxidation of PP. In addition, TGA analyses reveal that the traced blends can maintain better thermal properties, after irradiation. A significant increase of the crystallinity rate and a decrease of the melting temperature were detected for unfilled UV irradiated PP. This might result from chemi-crystallization which can occurr when chain entanglements are broken as a result of chain scissions. The freed segments produced by molecular chain scissions induce the formation of new crystalline structure in the amorphous zone, especially at high exposure temperature and thus provoke the growth of pre-existing crystals of PP. These changes in thermal behavior are less pronounced for traced blends.

After UV irradiation treatment, surface cracks appear on the surface of unfilled and filled BMU133 with T3. The intense surface cracks observed on the unfilled material is due to the photodegradation on the specimen surface. However, what is interesting here is the reduction of the surface cracks extent when adding T2 or T3 tracers. These cracks in the surface layer of degraded PP are observed by scanning electron microscopy (SEM). Furthermore, the mechanical tests confirm this finding and indicate a fundamental change in the behavior of the as-exposed blends. Such an effect is ascribed to chain scissions, accumulation of defects (carbonyls, etc.) and formation of surface cracks caused by the degradation process of PP.

To sum up, the addition of lanthanide complexes to polymers is of importance as i) it allows their rapid identification by UV fluorescence spectrometry in order to facilitate the sorting and recycling of end-of-life products ${ }^{[1]}$ and ii) limit the degradation of polymers under UV radiations. Thus, increased durability of polymer materials can be obtained by addition of lanthanide complexes such as T2 and T3.

\section{Acknowledgements}

The authors would like to thank the National Research Agency (ANR) for its contribution to the funding of this work and for providing industrial orientations and scientific supervision to the research. Authors also wish to acknowledge P. Alcouffe and the "Centre de Microstructures et d'analyses, plateforme Lyon 1" of the University Lyon1 for his assistance.

\section{References}

1. Aouachria, K., Quintard, G., Massardier-Nageotte, V., \& Belhaneche-Bensemra, N. (2014). The effect of Di-(-2-ethyl hexyl) phthalate (DEHP) as plasticizer on the thermal and mechanical properties of PVC/PMMA blends. Polimeros: Ciência e Tecnologia, 24(4), 428-433. http://dx.doi.org/10.1590/01041428.1588

2. Hachemi, R., Belhaneche-Bensemra, N., Massardier, V. (2014) Elaboration and characterization of bioblends based on PVC/ PLA. Journal of Applied Polymer Science, 131(7), 1-7. http:// dx.doi.org/10.1002/app.40045.

3. Ayoub, A., \& Massardier-Nageotte, V. (2012). The effect of UV-irradiation and molten medium on the mechanical and thermal properties of polystyrene-polycarbonate blends. Journal of Applied Polymer Science, 124(2), 1096-1105. http:// dx.doi.org/10.1002/app.35094.

4. Vignon, A., Ayoub, A., \& Massardier, V. (2013). The effect of gamma-irradiation and reactive extrusion on the structure and properties of polycarbonate and starch blends: a work oriented to the recycling of thermoplastic wastes. Journal of Applied Polymer Science, 127(5), 4168-4176. http://dx.doi. org/10.1002/app.38024.

5. Allen, N. S., \& Edge, M. (1992). Aspects of degradation and stabilization of polymers. In N.S. Allen, M. Edge. Fundamental of polymer degradation and stabilization (Chap 4). London: Elsevier Applied Science.

6. Shyichuk, A. V., Turton, T. J., White, J. R., \& Syrotynska, I. D. (2004). Different degradability of two similar polypropylenes as revealed by macromolecule scission and crosslinking rates. Polymer Degradation \& Stability, 86(2), 377-383. http://dx.doi. org/10.1016/j.polymdegradstab.2004.05.011.

7. Obadal, M., Cermak, R., Raab, M., Verney, V., Commereuc, S., \& Fraisse, F. (2005). Structure evolution of $\alpha$ - and $\beta$-polypropylenes upon UV irradiation: A multiscale comparison. Polymer Degradation \& Stability, 88(3), 532-539. http://dx.doi. org/10.1016/j.polymdegradstab.2004.12.014.

8. Výchopňová, J., Čermák, R., Obadal, M., Raab, M., Verney, V., \& Commereuc, S. (2007). The role of specific nucleation in polypropylene photodegradation. Polymer Degradation \& Stability, 92(10), 1763-1768. http://dx.doi.org/10.1016/j. polymdegradstab.2007.07.010. 
9. Commereuc, S., Scheirs, S., Verney, V., \& Lacoste, J. (1998). In situ detection of hindered amine stabilizer consumption in polymer through oxidation by indirect electron spin resonance. Journal of Applied Polymer Science, 69(6), 1107-1114. http:// dx.doi.org/10.1002/(SICI)1097-4628(19980808)69:6<1107::AIDAPP7>3.0.CO;2-K.

10. Chvátalová, L., Beníček, L., Berková, K., Čermák, R., Obadal, M., Verney, V., \& Commereuc, S. (2012). Effect of annealing temperature on phase composition and tensile properties in isotactic poly(1-butene). Journal of Applied Polymer Science, 124(4), 3407-3412. http://dx.doi.org/10.1002/app.35360.

11. Beníček, L., Chvátalová, L., Obadal, M., Čermák, R., Verney, V., \& Commereuc, S. (2011). Photodegradation of isotactic poly(1-butene): multiscale characterization. Polymer Degradation \& Stability, 96(10), 1740-1744. http://dx.doi.org/10.1016/j. polymdegradstab.2011.08.001.

12. Ammala, A., Hill, A. J., Meakin, P., Pas, S. J., \& Turney, T. W. (2002). Degradation studies of polyolefins incorporating transparent nanoparticulate zinc oxide UV stabilizers. Journal of Nanoparticle Research, 4(1), 167-174. http://dx.doi. org/10.1023/A:1020121700825.

13. Vink, P. (1983). The photo-oxidation of polyolefins - structural and morphological aspects. In N. S. Allen (Ed.), Degradation and stabilization of polyolefins (pp.213-246). London: Applied Science Publishers.

14. Albertson, A. C., Andersson, S. O., \& Karlsson, S. (1987). The mechanism of biodegradation of polyethylene. Polymer Degradation \& Stability, 18(1), 73-87. http://dx.doi. org/10.1016/0141-3910(87)90084-X.

15. Blinov, N. N., Popov, A. A., Rakovski, S., Stoyanov, A., Shopov, D. and Zaikov, G. E. (1989). Changes in the melting temperature, polydispersity and crystallinity of the components in a blend of high density polyethylene with polypropylene at deep ozone oxidation. Polymer Science U.S.S.R., 31(10), 2434-2439. http://dx.doi.org/10.1016/0032-3950(89)90103-2.

16. Rabello, M. S., \& White, J. R. (1997). Crystallization and melting behaviour of photodegraded polypropylene, I. Chemicrystallization. Polymer, 38(26), 6379-6387. http://dx.doi. org/10.1016/S0032-3861(97)00213-9.

17. Langlois, V., Audouin, L., Courtois, P., \& Verdu, J. (2003). Change of mechanical properties of crosslinked polyethylene during its thermo-oxidative aging. Die Angewandte Makromolekulare Chemie, 208(1), 47-64. http://dx.doi. org/10.1002/apmc.1993.052080105.

18. Blais, D., Carlsson, D. J., \& Wiles, D. M. (1972). Surface changes during polypropylene photo-oxidation: a study by infrared spectroscopy and electron microscopy. Journal of Polymer Science. Part A, Polymer Chemistry, 10(4), 10771092. http://dx.doi.org/10.1002/pol.1972.150100412.

19. Schoolenberg, G. E., \& Meijer, H. D. F. (1991). Ultra-violet degradation of polypropylene/2. Residual strength and failure mode in relation to the degraded surface layer. Polymer, 32(3), 438-444. http://dx.doi.org/10.1016/0032-3861(91)90447-Q.

20. Grassie, N., \& Scott, G. (1993). Polymer degradation and stabilization (pp. 13-28). Cambridge: Cambridge University Press,

21. Brown, H. E. (1976). Zinc oxide, properties and applications. New York: The New Jersey Zinc Company.

22. Mohanty, A. K., Misra, M., \& Drzal, L. T. (2001). Surface modifications of natural fibres and performances of the resulting biocomposites. Composite Interfaces, 8(5), 313-343. http:// dx.doi.org/10.1163/156855401753255422.

23. Zhao, H., \& Li, R. K. Y. (2006). A study on the photodegradation of zinc oxide $(\mathrm{ZnO})$ filled polypropylene nanocomposites. Polymer, 47(9), 3207-3217. http://dx.doi.org/10.1016/j. polymer.2006.02.089.

24. Atanassov, G., Thielsch, R., \& Popov, D. (1993). Optical Properties of $\mathrm{TiO} 2, \mathrm{Y} 2 \mathrm{O} 3$ and $\mathrm{CeO} 2$ thin films deposited by electron-beam evaporation. Thin Solid Films, 223(2), 288-292. http://dx.doi.org/10.1016/0040-6090(93)90534-V.

25. Sato, T., Katakura, T., Yin, S., Fujimoto, T., \& Yabe, S. (2004). Synthesis, UV-shielding properties of calcia-doped ceria nanoparticles coated with amorphous silica. Solid State Ionics, 172(1-4), 377-382. http://dx.doi.org/10.1016/j.ssi.2004.02.057.

26. Tessier, F., Cheviré, F., Muñoz, F., Merdrignac-Conanec, O., Marchand, R., Bouchard, M., \& Colbeau-Justin, C. (2008). Powder preparation and UV absorption properties of selected compositions in the $\mathrm{CeO} 2-\mathrm{Y} 2 \mathrm{O} 3$ system. Journal of Solid State Chemistry, 181(5), 1204-1212. http://dx.doi.org/10.1016/j. jssc.2008.02.034.

27. Bezati, F., Massardier, V., Balcaen, J., \& Froelich, D. (2011). A study on the dispersion, preparation, characterization and photo-degradation of polypropylene traced with rare earth oxides. Polymer Degradation \& Stability, 96(1), 51-59. http:// dx.doi.org/10.1016/j.polymdegradstab.2010.11.008.

28. Massardier, V., Louizi, M., Maris, E., Froelich, D. (in press). High shear dispersion of tracers in polyolefins for improving their detection. Polímeros: Ciência e Tecnologia.

29. Louizi, M., Massardier, V., Melis, F., Alcouffe, P., \& Cassagnau, Ph. (2014). High shear processing of (PP/EPR)/ silica nanocomposites: improvement of morphology and properties. International Polymer Processing, 29(1), 118-127. http://dx.doi.org/10.3139/217.2819.

30. Louizi, M., Massardier, V., \& Cassagnau, Ph. (2014). Contribution of high-shear processing to the compatibilization of (PP/EPR)/ PE ternary blends. Macromolecular Materials and Engineering, 299(6), 674-688. http://dx.doi.org/10.1002/mame.201300268.

31. Vergnes, B., Valle, G. D., \& Delamare, L. (1998). A global ID model for polymer flows in corotating twin screw extruders. Polymer Engineering and Science, 38(11), 1781-1792. http:// dx.doi.org/10.1002/pen.10348.

32. Morlat, S., Mailhot, B., Gonzalez, D., \& Gardette, J. L. (2004). Photo-oxidation of polypropylene/montmorillonite nanocomposites. 1. influence of nanoclay and compatibilizing agent. Chemistry of Materials, 16(3), 377-383. http://dx.doi. org $/ 10.1021 / \mathrm{cm} 031079 \mathrm{k}$.

33. Qin, H., Zhang, S., Liu, H., Xie, S., Yang, M., \& Shen, D. (2005). Photo-oxidative degradation of polypropylene/montmorillonite nanocomposites. Polymer, 46(9), 3149-3156. http://dx.doi. org/10.1016/j.polymer.2005.01.087.

34. Zoepfl, F., Markovic, V., \& Silverman, J. (1984). Differential Scanning Calorimetry Studies of Irradiated Polyethylene: I. Melting Temperatures and Fusion Endotherms. Journal of Polymer Science. Part A, Polymer Chemistry, 22(9), 2017 2032. http://dx.doi.org/10.1002/pol.1984.170220907.

35. Zanetti, M., Camino, G., Reichert, P., \& Mulhaupt, R. (2001). Thermal behaviour of poly(propylene) layered silicate nanocomposites. Macromolecular Rapid Communications, 22(3), 176-180. http://dx.doi.org/10.1002/1521-3927(200102)22:3<176::AIDMARC176>3.0.CO;2-C.

36. Ferreira, F. G. D., Lima, M. A. G. A., Almeida, Y. M. B., \& Vinhas, G. M. (2009). Evaluation of photodegration of LDPE/ modified starch blends. Polímeros, Ciência e Tecnologia, 19(4), 313-317. http://dx.doi.org/10.1590/S0104-14282009000400011.

37. Ouederni, M., \& Phillips, P. J. (1995). Influence of morphology on the fracture toughness of isotactic polypropylene. Journal of Polymer Science. Part B, Polymer Physics, 33(9), 1313-1322. http://dx.doi.org/10.1002/polb.1995.090330901.

38. Fisher, W. K., \& Corelli, J. C. (1981). Effect of Ionizing radiation on the chemical composition, crystalline content and structure, and flow properties of PTFE. Journal of Polymer Science. Part A, Polymer Chemistry, 19(10), 2465-2493. http:// dx.doi.org/10.1002/pol.1981.170191010. 